\title{
Formação de Doutores no País e no Exterior: Estratégias Alternativas ou Complementares?*
}

\author{
Léa Velho
}

$\mathrm{D}$ esde a emergência da ciência moderna no período da revolução científica, a formação de pessoas para desempenhar atividades de investigação é feita por outros pesquisadores, através de uma relação do tipo "mestre e aprendiz". Tendo em vista que a competência dos pesquisadores qualificados, por uma série de razões, não é homogênea no mundo, o esforço de formação de pesquisadores de um dado país sempre contou, em alguma medida, com a expertise instalada em outros países. No século XIX, por exemplo, com a experiência pioneira de profissionalização da pesquisa científica e a criação de postos permanentes de trabalho para investigadores em tempo integral, tanto nas universidades e institutos de pesquisa públicos, como nos laboratórios de P\&D das indústrias químicas da Alemanha, este país passou a ser o principal pólo de atração de pessoas, de todo o mundo, que queriam se treinar como pesquisadores (Ben-David,

*Trabalho realizado como consultora no âmbito do projeto "Inserção Acadêmica de Doutores Formados no País e no Exterior", coordenado pelo Prof. Jacques Velloso, com financiamento da Coordenação de Aperfeiçoamento de Pessoal de Nível Superior CAPES e do Conselho Nacional de Desenvolvimento Científico e Tecnológico - CNPQ, Brasília, junho de 2000.

DADOS - Revista de Ciências Sociais, Rio de Janeiro, Vol. 44, nº 3, 2001, pp. 607 a 631. 
1971). Assim, sabe-se que a formação da comunidade científica norte-americana em áreas como a química e a agricultura se assentou no modelo e na capacitação adquiridos pelos jovens americanos que foram se treinar na Alemanha, nos laboratórios de pesquisadores como Liebig, entre outros (Rossiter, 1975).

Evidentemente, conforme um país qualifica seus próprios pesquisadores, vai adquirindo competências que, somadas às outras condições necessárias (emprego, financiamento, reconhecimento social etc.), tornam possível a formação de pesquisadores dentro de suas próprias fronteiras. Essa é a trajetória histórica da maioria dos países que conseguiu estabelecer um sistema significativo de treinamento e formação de novos pesquisadores. Nos tempos mais recentes, esta também tem sido a trajetória de alguns países que, até meados do século XX, ainda eram fortemente dependentes de outros para formar recursos humanos para pesquisa. Entre estes se destacam países asiáticos como o Japão, a Coréia do Sul e a China e, na América Latina, o Brasil, que investiram pesadamente para criar e consolidar sistemas de pós-graduação internos.

Quando um país consegue ter capacitação interna, em quantidade e qualidade, pode ele prescindir totalmente de formar pesquisadores em outros países? Tal nível de auto-suficiência é possível ou desejável?

Não existe resposta simples a estas questões. Elas envolvem dimensões variadas e, dependendo da perspectiva de quem as responde, assim como das premissas, podem ter resposta positiva ou negativa. $\mathrm{O}$ que se pode dizer, com razoável grau de segurança, é que nenhum país adotou ainda essa política. Ou seja, mesmo aqueles que constituíram "os melhores" sistemas de formação de pesquisadores em determinada época, nunca deixaram de investir no treinamento de novos pesquisadores em outros países. Vejamos, então, alguns exemplos recentes.

Os Estados Unidos da América são, sem dúvida, o país que apresenta o maior, mais complexo e mais reconhecido sistema de pós-graduação do mundo. De fato, tem sido afirmado que "o sistema de pós-graduação dos Estados Unidos, especialmente no nível de doutorado, é a inveja do mundo" (Chubin e Robinson, 1992:334). Tal sistema teve um crescimento sistemático e contínuo por mais de vinte anos até atingir 440.000 estudantes em 1993. De 1975 a 1993 cresceu a

\section{8}


uma taxa de $2 \%$ ao ano e então estabilizou em termos gerais, ainda que algumas áreas como matemática, engenharia e computação tenham diminuído a uma taxa de $1 \%$ ao ano desde então e outras, como as ciências biológicas, tenham continuado a crescer até hoje ${ }^{1}$.

Como resultado desse crescimento, no ano de $1995^{2}$ as diferentes universidades americanas tinham cerca de 424 mil estudantes matriculados em cursos de doutorado. Uma parcela significativa desses estudantes era composta por estrangeiros: de 1982 a 1992 o número de estudantes de doutorado estrangeiros nos EUA cresceu a uma taxa anual de 5\%. Ainda que esta participação de estrangeiros no alunado de doutorado tenha experimentado uma pequena, mas persistente, diminuição desde 1992, em 1995 ela somava cerca de 100.000 estudantes, isto é, $24 \%$ dos matriculados.

Essas mesmas universidades americanas outorgaram um total de 44.855 títulos de doutor em 1995, dos quais, cerca de $65 \%$ foram concedidos a cidadãos americanos ${ }^{3}$. Quando se olha apenas os títulos concedidos nas chamadas áreas de ciências e engenharias ${ }^{4}$ pode-se notar que o número de estrangeiros titulados como doutor nas universidades americanas cresceu de 31\% em 1986 para 47\% em 1995 (em algumas áreas do conhecimento, como matemática e ciência da computação, os estrangeiros receberam $50 \%$ dos títulos de doutor concedidos e, em engenharia, esta proporção chegou a 58\%. Estudantes da China, Índia, Coréia do Sul e Taiwan representam mais da metade desse número ${ }^{5}$.

Até 1992, cerca de metade dos estudantes estrangeiros alegava ter planos de permanecer nos EUA depois de obter o doutorado. Uma proporção significativamente menor (um terço) tinha chances concretas de fazê-lo, isto é, tinha ofertas para isso. A proporção de recém-doutores que de fato permanece nos EUA varia muito de país para país: aqueles de países asiáticos, que são os mais numerosos, também são os mais tendentes a ficar. Um estudo recente mostra, por exemplo, que cerca de $80 \%$ dos indianos e $90 \%$ dos chineses que se doutoraram nos EUA em 1990 e 1991, em 1995 ainda estavam trabalhando lá (Finn, 1997). O valor equivalente para os oriundos do Reino Unido é cerca de $45 \%$ e de $40 \%$ para aqueles da Alemanha. De todos os países para os quais há informações, o Brasil é aquele com menor porcentagem de recém-doutores que permanece nos EUA (em torno de 18\% no período de 1990 a $1996^{6}$ ). Essas taxas de permanência também 
variam nas diferentes áreas do conhecimento, sendo mais altas nas ciências físicas e nas engenharias e mais baixas nas ciências biológicas e nas sociais.

Do exposto percebe-se claramente que um enorme contingente de novos doutores, sejam cidadãos americanos ou estrangeiros, é incorporado à força de trabalho norte-americana a cada ano, o que dá uma idéia da dimensão e do dinamismo do sistema norte-americano de formação de novos pesquisadores.

Neste ponto cabe perguntar: também os Estados Unidos enviam pessoas para serem treinadas em outros países? Sabe-se que o número de americanos que estudam fora de seu país no nível de doutorado é infinitamente menor do que aquele de estrangeiros para esta finalidade nos Estados Unidos. Tradicionalmente, quando os estudantes americanos se deslocam para outros países, tendem a fazê-lo por períodos de tempo mais curtos (e não doutorados completos) e para treinamentos relacionados a línguas, história e cultura (OECD, 1998:57). Entretanto, recentemente, pode-se notar uma conscientização crescente por parte do aparato de política educacional e científica nos Estados Unidos da importância de uma educação internacional como preparação para o trabalho qualificado na "economia global do século XXI". Referida como "competência transnacional", essa educação envolve uma combinação de habilidades culturais e técnicas que incluem: a) conhecimento do desenvolvimento comercial, técnico e cultural em locais variados; b) compreensão de costumes e estratégias de negociação locais; c) facilidade com pelo menos um outro idioma além do inglês; d) facilidade com computadores; e) habilidades em tecnologia e conscientização de seus diferentes contextos culturais. Programas governamentais de apoio às experiências em países estrangeiros por parte da NSF têm crescido a cada ano e envolvem os vários níveis educacionais (da graduação ao pós-doutorado) e de experiência em pesquisa (para pesquisadores jovens e seniores) ${ }^{7}$.

Além disso, um contingente significativo de doutores americanos vai para o exterior para um pós-doutorado ou como pesquisadores visitantes - estimativas indicam que cerca de 14.000 doutores nascidos norte-americanos estavam vivendo no exterior em 1995; considerados todos os doutores com cidadania americana e aqueles com visto permanente de residência, esse número sobe para $19.600^{8}$.

\section{0}


O que estes dados indicam é que, mesmo sendo um país claramente importador de cérebros, que atrai para seu território tanto o conhecimento incorporado em pesquisadores das mais diversas culturas ${ }^{9}$, quanto o financiamento de empresas das mais distintas nacionalidades que lá estabelecem seus centros de $\mathrm{P} \& \mathrm{D}$ para ficarem mais próximos da expertise técnica e do conhecimento científico, os Estados Unidos apresentam uma significativa mobilidade internacional de seus pesquisadores (sem contar a enorme mobilidade interna num país com dimensões continentais e que conta com centros de excelência em todas as regiões).

No Japão, a partir do início dos anos 90 foi-se construindo um consenso sobre a importância da formação de doutores para fazer face à competitividade industrial e à inovação. Os tomadores de decisão sobre C\&T foram percebendo que a continuidade da estratégia de enfatizar a pesquisa para adaptar tecnologia importada, tão bem-sucedida até então, não iria levar o país à capacitação necessária para o desenvolvimento de novas tecnologias ${ }^{10}$. Estas, teriam que ser apoiadas em pesquisa básica, cuja mobilização era vista como essencial para o desenvolvimento sustentável de longo prazo. Isso resultou em uma série de reformas da educação pós-graduada que incluiu: o aumento da escala dos programas, a introdução de um maior número de disciplinas (semelhante ao sistema americano), a diversificação das fontes de financiamento (inclusive pesquisa cooperativa com a indústria) e o aumento da mobilidade de seus recursos humanos através do treinamento dos mesmos em outros países ou do envio de cientistas já formados para períodos fixos de permanência em universidades de outros países avançados ${ }^{11}$.

Em decorrência dessas reformas, os programas de pós-graduação do Japão tiveram uma enorme expansão, tendo o número de estudantes de doutorado crescido a uma taxa de $15 \%$ ao ano entre 1990 e 1995 . O objetivo era chegar ao ano 2000 com o dobro de estudantes de doutorado que o país tinha em 1994, ou seja, passar de 138.000 para 277.000 estudantes. No ano de 1994, o número de estudantes estrangeiros de doutorado no Japão girava em torno de 17.800 (cerca de 13\% do total), três quartos dos quais eram da China e da Coréia ${ }^{12}$.

Mesmo com essa política agressiva de expansão dos programas e do alunado de pós-graduação dentro do país, o Japão ainda envia um significativo número de estudantes de doutorado ao exterior: no ano 
acadêmico de 1993-94, havia quase 50.000 japoneses estudando nos EUA, dos quais cerca de 8.000 faziam doutorado pleno ${ }^{13}$, boa parte deles com financiamento da indústria japonesa. Somando o número de doutores japoneses titulados no Japão (13.700) com aqueles que obtiveram seus títulos nos EUA $(253)^{14}$ no ano de 1995, chega-se a aproximadamente 14.000 doutores formados naquele ano apenas, o que é um contingente respeitável, particularmente quando se leva em conta a taxa de crescimento que se planejava manter para dobrar esse número até o ano 2000.

Também em 1995, os países da Europa Ocidental e Oriental (Rússia incluída) juntos concederam 78.791 títulos de doutor, cerca de $70 \%$ a mais que os Estados Unidos ${ }^{15}$. Considerando apenas os países da União Européia, os valores são ainda mais altos - 60.364 doutorados concluídos. A Alemanha foi a maior responsável por este contingente, tendo formado 22.404 doutores, seguida pela França e pelo Reino Unido que titularam, cada um, quase 10.000 doutores naquele ano. Assim como nos Estados Unidos, uma proporção significativa desses títulos foi obtida por estrangeiros. Ainda que não se disponha dos dados para todas as áreas do conhecimento, sabe-se que estudantes estrangeiros receberam $50 \%$ dos títulos de doutor em engenharia concedidos no Reino Unido e cerca de 30\% daqueles em ciências naturais outorgados pelas universidades francesas. A Alemanha recebe menor proporção de estudantes estrangeiros, dadas as dificuldades lingüísticas, mas mesmo assim, em torno de $15 \%$ dos títulos de doutor em engenharia foram concedidos a estrangeiros naquele país em 1995.

Mesmo contando com sistemas robustos de pós-graduação, de qualidade inquestionável (tanto é assim que em 1999, pela primeira vez depois da Segunda Guerra, a produção científica da Europa ultrapassou a dos EUA, de acordo com dados do SCI), e mesmo sendo pólos de atração conhecidos para estudantes de doutorado de todo o mundo, os países europeus exibem contingentes significativos de estudantes de doutorado, mas particularmente de pós-doutorado, nos Estados Unidos. A estimativa é que em 1995 havia cerca de 9.000 estudantes alemães nos EUA, metade dos quais em nível de pós-graduação ${ }^{16}$. No que diz respeito à França, um estudo detalhado revelou que, no período de 1990 a 1995, manteve-se, anualmente, um contingente estável de cerca de 7.000 pesquisadores, pós-doutorandos e estudantes de doutorado franceses, nos EUA (Carlson e Martin-Rovet, 1995). Isso

\section{2}


sem falar na mobilidade interna desses estudantes (seja de graduação ou de pós-graduação) e pesquisadores entre os próprios países europeus. Tal mobilidade, ou internacionalização como tem sido chamada por alguns autores, tem claro objetivo político de conformar uma comunidade científica européia, com identidade própria e que extrapole o senso exclusivo de um único Estado-nação (Blume, 1991).

No caso da China, vale ressaltar que o número de mais de 4.000 doutores titulados internamente em 1996 reflete um aumento considerável em apenas cinco anos. Em 1991 a China havia formado no país menos de 1.000 doutores, o que revela uma fantástica taxa de crescimento anual ${ }^{17}$. Isso foi possível através de financiamentos internacionais solicitados pela China como parte de seu plano econômico para fortalecer os setores de produção de alta tecnologia. Tais empréstimos melhoraram a instrumentação científica, os laboratórios científicos e de computação e permitiram que pesquisadores seniores passassem algum tempo no exterior mas, acima de tudo, que um enorme contingente de jovens se formasse no exterior no nível de doutorado ${ }^{18}$. Assim, entre 1980 e 1988, cerca de 20.000 estudantes de pósgraduação, a grande maioria financiada pelo governo chinês, retornaram titulados dos Estados Unidos (Orleans, 1988), tornando-se um componente fundamental dos recursos científicos da China, sem os quais teria sido impossível a expansão verificada do sistema interno de pós-graduação.

Os conflitos sociais de 1989 na China, que culminaram com o massacre de estudantes na Praça da Paz Celestial, reverteram tanto a política oficial de envio de estudantes chineses ao exterior quanto a taxa de retorno daqueles que lograram sair para esse fim. Desse modo, apenas uma parcela muito pequena dos cerca de 33.000 chineses matriculados nos cursos de doutorado em universidades americanas em 1995 tinha financiamento do governo chinês. Além disso, a proporção daqueles formados depois de 1989 que planejam ficar nos EUA é bastante alta: mais da metade dos cerca de 14.000 doutores chineses em ciências e engenharias (excluídas as áreas de administração, economia, educação, medicina, letras e outras consideradas non-science and engineering fields pela NSF) titulados nos EUA entre 1989 e 1995 tinha planos definitivos (e ofertas de emprego ou de pós-doutorado) para permanecer naquele país ${ }^{19}$. 
A despeito da diminuição do contingente de chineses treinados no exterior e da grande proporção destes que não retorna ao seu país de origem, o número de doutores sendo incorporado às universidades chinesas vem crescendo a uma taxa fantástica. Um movimento de intensidade semelhante (ainda que menor em termos absolutos, por razões óbvias) pode ser observado no caso da Coréia do Sul.

A Coréia do Sul expandiu consideravelmente seu sistema de pós-graduação a partir de 1980. Para isso, criou o Instituto Avançado de Ciência e Tecnologia e, mais recentemente, a Pohang University of Science and Technology (financiada por industriais) cuja principal função é o ensino de pós-graduação associado à pesquisa. Como resultado desse esforço, o número de títulos de doutorado concedidos pelas instituições coreanas passou de 945 em 1990 para cerca de 2.200 em 1995, considerando apenas as áreas de ciências e engenharias ${ }^{20}$.

O número de estudantes coreanos nos EUA tem sido tradicionalmente elevado há duas décadas. Em 1995 havia perto de 37.000 coreanos estudando naquele país, metade dos quais na pós-graduação, e mais de 1.000 coreanos receberam seus títulos de doutorado nos EUA ${ }^{21}$. Desde 1995 esses números têm diminuído graças ao aumento da capacitação interna da Coréia na formação de doutores. Ainda assim, nas engenharias, o número de doutores coreanos formados nos EUAé maior do que aquele de doutores titulados pelas próprias universidades coreanas ${ }^{22}$. A Coréia do Sul, por razões estratégicas, não abre mão da formação de parte significativa de seus recursos humanos para pesquisa nas universidades americanas que mais contribuem para o avanço do conhecimento. Vale lembrar também que a Coréia é o país que mais envia estudantes de pós-graduação ao Japão.

O investimento feito pela Coréia do Sul, não apenas na formação pós-graduada, mas em todos os níveis educacionais, certamente tem tido retornos econômicos. Dados recentes indicam que este país continua a patentear fortemente em tecnologias de comunicação e processos usados para manufaturar aparelhos semicondutores, informação dinâmica e estática, sistemas de display e outras tecnologias. Juntamente com Taiwan, a Coréia do Sul é o principal fornecedor de computadores e periféricos para os Estados Unidos. Os dados de patentes mostram que a Coréia continua a desenvolver novas tecnologias e inovações que provavelmente servirão como base para uma presença

\section{4}


crescente desse país no mercado dos EUA, em especial, e no mercado global $^{23}$.

Dos dados apresentados acima para os países selecionados, é possível inferir alguns traços comuns a todos eles em relação à formação de recursos humanos para pesquisa: todos querem expandir seu quadro de doutores (ou seja, a qualificação de seus pesquisadores) e todos querem que esses pesquisadores tenham inserção internacional, para o que há um incentivo à mobilidade desses recursos humanos. Quais as razões para a persistência e o aumento dessa mobilidade no treinamento e na carreira de pesquisador?

Não há uma razão única. Para muitos países da Ásia, a atração de estudantes para as áreas de ciências e engenharias, assim como a expansão do acesso e participação de estudantes estrangeiros, são aspectos importantes de suas estratégias de crescimento econômico. Universidades da Austrália, por exemplo, estão incisivamente recrutando estudantes estrangeiros, e o governo está incluindo o oferecimento de serviços educacionais para os países do Pacífico como parte de seu planejamento econômico nacional. O plano de longo prazo é ter 2,8 milhões de estudantes estrangeiros no ano de 2010. Para um país geograficamente isolado como a Austrália, receber estudantes estrangeiros é uma das maneiras para alcançar inserção internacional ${ }^{24}$.

Poder-se-ia listar um número infindável de razões particulares para que cada país queira aumentar sua força de trabalho em $P \& D$ e se articular internacionalmente. Existe, entretanto, um motivação mais geral, estreitamente ligada ao contexto mundial de hoje: a globalização e a necessidade imposta por esse processo para que as economias modernas sejam "baseadas no conhecimento".

Em um levantamento recente realizado entre os estudantes que ingressaram nas universidades americanas em 1998, apenas 28\% declararam que tinham intenção de finalizar sua educação com o título de graduado - todos os demais pretendiam seguir algum tipo de pós-graduação: 39\% pretendiam obter um título de Mestre em alguma área profissional (particularmente em business, engenharia e computação), $14 \%$ um doutorado acadêmico, $7 \%$ um doutorado profissional (particularmente em medicina, veterinária e odontologia) e 3\% um doutorado em disciplinas jurídicas ${ }^{25}$. A situação na Europa, em contextos e esquemas educativos distintos, exibe tendências compa- 
ráveis ${ }^{26}$. Ainda que não haja dados equivalentes disponíveis para o Brasil, não há razão para duvidar que a tendência em termos de aumento da demanda para estudos pós-graduados seja diferente daquela que se verifica nos EUA, na Europa e nos países asiáticos.

Esse aumento da demanda por educação pós-graduada deriva, entre outros fatores, de uma conscientização social do valor da educação e da formação para o mercado de trabalho. Evidentemente, esse valor está diretamente associado à importância da ciência e da tecnologia como fatores de produção e da inovação tecnológica na competitividade das empresas e das nações. Incontáveis estudos, análises e reflexões têm enfatizado a necessidade de um país manter sua própria estrutura de pesquisa básica, a fim de sustentar seu desenvolvimento tecnológico ${ }^{27}$. Tais estudos têm apontado também que a importância da ciência varia setorialmente e que as relações entre $C \& T$ e inovação são sutis, indiretas e variadas (Mansfield, 1998).

Essa nova visão da relação entre pesquisa básica e inovação tecnológica interpreta o conhecimento científico como embutido em indivíduos e organizações, sendo que seus benefícios fluem através de treinamento, aprendizagem e redes. O investimento público é justificado como provedor de treinamento científico e do acesso das nações a redes internacionais de pesquisa. Diferentemente do argumento economicista tradicional da falha de mercado, o conhecimento fundamental não é mais visto como um bem público; ao contrário, demanda custoso treinamento para sua adequada interpretação e virtual aplicação econômica (OECD, 1992).

Essa corrente parte do pressuposto teórico de que o processo de inovação é constituído de diversas interações entre as esferas de produção econômica e a C\&T. Ao valorizar este aspecto, ressalta-se o papel do elemento humano no processo inovativo. Portanto, a inovação estaria embutida em indivíduos inseridos em um conjunto de instituições (tais como empresas, institutos de pesquisa, universidades) e os benefícios gerados pelas inovações fluiriam através de redes compostas por esses elementos.

Em síntese, o argumento central é que "o melhor investimento que um país pode fazer em desenvolvimento científico é a formação de recursos humanos de primeira linha. O conhecimento incorporado (knowledge embodied) nesses indivíduos é que vai permitir não apenas

\section{6}


o avanço da ciência, mas também a aplicação dessa ciência à inovação tecnológica e ao desenvolvimento econômico" (Pavitt, 1991:113) ${ }^{28}$. Tal conhecimento de fronteira extrapola o conteúdo mesmo da ciência e inclui outras formas de conhecimento, tais como modos de trabalhar e de gestão da pesquisa, acesso a outros grupos em linhas complementares, acesso à literatura e capacidade de identificar o que é relevante etc. Esse tipo de conhecimento só se "incorpora" nos indivíduos que tiveram oportunidade de se formar em programas de qualidade e de observar grupos, além de ter vivência com eles, que trabalham na fronteira da ciência, aqueles que definem as regras do jogo científico.

As habilidades desenvolvidas por pessoal envolvido em pesquisa básica (especialmente estudantes de pós-graduação) permitem benefícios econômicos quando indivíduos se profissionalizam, carregando conhecimento tácito e codificado para a atividade econômica ${ }^{29}$. É, portanto, com base nesse argumento que os países avançados e os em desenvolvimento aqui tratados investem tanto na formação de novos pesquisadores quanto em iniciativas de inseri-los nas redes internacionais.

Que lições se pode tirar desse quadro para o caso brasileiro? Sabe-se que o Brasil tem feito esforços consideráveis e razoavelmente bem-sucedidos para implantar e expandir uma estrutura de educação pós-graduada que tem sido apontada como exemplo a ser seguido por outros países em desenvolvimento. Com base nesse sucesso, não faltam vozes a sugerir que está na hora de diminuir o envio de estudantes brasileiros para formação no exterior em nível de doutorado, uma vez que nossa pós-graduação já atenderia às necessidades do país.

Por tudo que se apresentou acima, pode-se perceber a fragilidade desta assertiva. Mesmo que o Brasil já pudesse formar o número de doutores de que necessita, ainda assim a formação de pesquisadores no exterior seria fundamental como elemento-chave de inserção do país nas redes internacionais de C\&T.

Além disso, tem que se levar em consideração a questão da qualidade da nossa pós-graduação. Apenas 127 dos 667 cursos de doutorado (cerca de 20\%) foram avaliados com notas 6 e 7, e mesmo destes não se 
sabe ainda quantos possuem qualidade internacional já que os comitês de avaliação internacional ainda não terminaram seu trabalho.

Existe evidência suficiente na literatura de que a qualidade dos programas de doutorado depende da sua capacidade de investigação. Na medida em que um número muito pequeno de programas brasileiros têm qualidade internacional, é evidente que não se pode prescindir de formar doutores nos melhores programas fora do país. Ainda que isto seja patente, vale lembrar que uma série de estudos tem apontado para a importância da relação "mestre-aprendiz" e do ambiente institucional na formação de pesquisadores (Long e McGinnis, 1985; Stricker, 1994). O argumento central desses trabalhos é que o fato de estarem em departamentos de primeira linha, interagirem com pesquisadores de alta reputação, terem recursos e infraestrutura superiores para fazer suas pesquisas, faz com que os doutorandos desses ambientes institucionais tenham vantagens cognitivas e sociais. Uma vez colocados estrategicamente no sistema de estratificação na fase inicial de sua formação, suas possibilidades de sucesso na carreira tornam-se maiores, seja pelos contatos que fazem, seja pelas maiores oportunidades de aprendizagem, seja pelo "modelo" que incorporam. Parte desse modelo é a aquisição de hábitos de publicação, de trabalho em equipe, de colaboração com pesquisadores de diferentes países, de colaboração com o setor produtivo.

Uma vez que se consiga um razoável grau de concordância, entre os envolvidos na tomada de decisão, sobre a importância de se manter o programa de formação de recursos humanos para pesquisa no exterior, ainda caberia perguntar: em que nível e de que forma isso deve se dar como prioridade? No pós-doutorado ou no doutorado? E o doutorado-sanduíche? Vejamos alguns aspectos relevantes dessa questão.

Com a diminuição do número de cargos nas universidades, com o aumento do número de doutores e com o crescimento da atividade de pesquisa e do financiamento da mesma ${ }^{30}$, a pesquisa nas universidades de vários países avançados tem cada vez mais se assentado no trabalho de pós-doutorado. Nos EUA, por exemplo, a maioria das posições universitárias de pós-doutorado nas ciências exatas, biológicas e nas engenharias é ocupada por estrangeiros. O Reino Unido e a França também têm uma alta proporção de pós-doutores estrangeiros, embora o número de posições para pós-doutores nesses países seja muito menor. O Japão está se empenhando no sentido de melhorar a

\section{8}


qualidade da ciência básica nas suas universidades e uma estratégia usada é oferecer mais bolsas de pós-doutorado para japoneses e estrangeiros ${ }^{31}$.

Parece, então, que o papel dos pós-doutorados nas universidades dos países avançados é fazer a pesquisa, na maior parte das vezes de interesse das empresas que a financiam e sob a liderança de um professor de prestígio, sem onerar a universidade (que expande seu número de pesquisadores-doutores sem ter com eles compromissos institucionais, já que a escolha do pós-doutorando é de inteira responsabilidade do professor que detém o financiamento). Enfim, o recebimento de grandes contingentes de pós-doutorandos estrangeiros nas universidades dos países avançados é uma política que atende, em última instância, aos interesses das próprias universidades ${ }^{32}$.

Nessa circunstância, o que se deve esperar do programa de pós-doutorado no exterior vis-à-vis o de doutorado e o de doutorado-sanduíche mantidos pelas agências brasileiras? Qual a lógica da prioridade que tem sido dada à formação no nível de pós-doutores e de doutorado-sanduíche em detrimento do doutorado pleno no exterior? Tal lógica se respalda numa reflexão com base em evidências derivadas de estudos?

Como argumentei acima, a tendência do pós-doutorado é se caracterizar como uma oportunidade de complementação de formação através de um trabalho de pesquisa. Evidentemente que um jovem doutor ainda tem muito que avançar em sua formação e a oportunidade de trabalho em uma equipe de qualidade, com liderança em certo tema e financiamento, contribui muito para isso. Entretanto, essa formação é muito mais especializada, se restringindo, em geral, ao contato com os membros da equipe, e pode ocorrer em quase total isolamento do restante da universidade, na medida em que o pós-doutor não tem que cumprir disciplinas nem se envolver com qualquer outro laboratório/departamento/grupo que não seja aquele em que trabalha. Quando isso se dá com os doutores que obtiveram seus títulos nos EUA, não há efeitos negativos: a pessoa já passou pelo sistema de treinamento formal, já foi submetida ao funcionamento da universidade, já freqüentou diversos laboratórios e pode escolher onde e com quem quer trabalhar. Além disso, para essas pessoas, assumir uma posição como pós-doutor é continuar a viver nos EUA, numa fase em 
que ela própria (e a família) já superou os problemas de adaptação com o idioma, a cultura etc.

A política brasileira de concessão de bolsas de pós-doutorado no exterior, no entanto, tende a dar prioridade ao indivíduo que fez o doutorado aqui e que, durante um ano no exterior, terá que se submeter a todo o processo de adaptação, além de absorver o que o sistema tem a oferecer a ele. Com certeza, vai trabalhar em alguma equipe bem financiada, enquanto é mantido no exterior com recursos brasileiros. As agências de financiamento têm conhecimento de que o bolsista vai prestar serviço para alguma equipe do exterior, tanto é que nenhuma delas concorda com o pagamento de taxas escolares para as universidades que recebem nossos pós-doutores, no entendimento de que estes prestam serviços às universidades. Assim, a lógica de incentivar pós-doutoramentos no exterior adotada pelas agências parece residir na reflexão de que, apesar das dificuldades apontadas e das limitações em termos de uma formação mais completa, esse tipo de treinamento oferece ao recém-doutor uma oportunidade de trabalho com uma equipe de qualidade, abre caminho para canais de publicação em revistas de primeira linha, estabelece contatos com o mundo científico mainstream e tudo isso a um custo relativamente baixo quando comparado com o custo do doutorado pleno (já que o primeiro não paga taxas universitárias e se estende por, no máximo, dois anos). Alguns acrescentariam como vantagem do pós-doutorado que a tendência entre estes de permanecer no exterior após o treinamento é menor que no caso dos doutores. Isto, no entanto, é motivo de debates, e está a merecer estudos mais aprofundados ${ }^{33}$. Apesar de os dados disponíveis na NSF dos EUA apontarem uma baixa proporção de doutorandos brasileiros que permanecem no exterior comparativamente a outros países, mesmo os europeus desenvolvidos como a Alemanha e o Reino Unido, o estado atual do mercado de trabalho para doutores no Brasil é tão desestimulante que o crescimento da evasão de cérebros não é uma hipótese a ser desprezada. Várias perguntas necessitam ser respondidas em relação a essa questão.

A despeito da prioridade ao pós-doutorado, a proporção desse tipo de bolsa tem se mantido estável desde 1996, perfazendo não mais que $10 \%$ do total de bolsas no exterior concedidas pela CAPES ${ }^{34}$. Além disso, ainda que não existam estatísticas disponíveis sobre a proporção dessas bolsas que é utilizada por recém-doutores (os pós-doutorandos no sentido em que o termo é usado na maioria dos outros países, 
ou seja, no máximo cinco anos após o doutorado que é, em geral, obtido em torno dos 30 anos de idade), sabe-se que o programa serve primordialmente a professores-doutores das universidades brasileiras. Estes, muito provavelmente, são pessoas mais velhas e mais experientes quando se dirigem ao exterior como pós-doutores ${ }^{35}$. Assim, uma parte, talvez a maior, do programa de pós-doutorado no exterior da CAPES (e também o da Fundação de Amparo à Pesquisa do Estado de São Paulo - FAPESP, que atende quase exclusivamente aos pesquisadores com vínculo com instituições no Estado de São Paulo e, em menor medida, o do CNPQ, que é mais "livre" em relação ao vínculo empregatício) seja muito mais um programa de reciclagem e de experiência internacional para pesquisadores já formados do que um programa de formação de pesquisadores propriamente dito ${ }^{36}$. Nessas circunstâncias, não se pode dizer, stricto sensu, que o programa de pós-doutorado é mais eficiente para a formação de pesquisadores do que o de doutorado pleno porque ambos, no caso brasileiro, servem a funções diferentes: reciclagem, o primeiro; formação mesmo, o segundo $^{37}$. A despeito da importância que o programa de pós-doutorado tem para a qualidade dos programas de pós-graduação, pela oportunidade que concede aos docentes de interagir e conviver com equipes de alta reputação científica no exterior e de se inserir nas redes internacionais, é necessário que se coloque a função e o impacto desse programa no seu devido lugar. Em outras palavras, para que tenha impacto na formação, a inserção de parte de nossos futuros pesquisadores no mundo internacional da ciência deve se dar no período de formação propriamente dita (e mais cedo na vida, eu ousaria dizer, apesar da temeridade da assertiva). Isso pode se dar através de um programa de pós-doutorado mais direcionado para os recém-doutores, independentemente da vinculação deles com alguma instituição brasileira (com maior risco de evasão, portanto) ou, durante o doutorado. Aqui, cabe perguntar: doutorado pleno no exterior ou doutorado-sanduíche?

Desde a sua criação, o programa de doutorado-sanduíche no exterior tem ganho muitos adeptos e defensores, tanto na comunidade científica, quanto entre os estudantes de doutorado e os técnicos das agências. Tanto é assim que a participação desse tipo de apoio no total de bolsas no exterior da CAPES cresceu de 12\% em 1996 para cerca de 20\% em 2000, ao passo que o apoio ao doutorado pleno decresceu de $74 \%$ para $48 \%$ no mesmo período ${ }^{38}$. O argumento central dos defensores 
dessa política é que a bolsa de doutorado-sanduíche é mais barata (porque paga taxas acadêmicas, quando o faz, para apenas um, no máximo dois anos, além de pagar a mensalidade dos bolsistas em moeda forte somente para o mesmo período), evita a permanência de doutores no exterior e os problemas de falta de adaptação no retorno, ao mesmo tempo que propicia aos doutorandos treinamento e experiência de estudo/pesquisa no exterior. Ou seja, ganha-se o mesmo que com o doutorado pleno, com vantagens e a um custo menor. Será?

Esta pergunta não foi devidamente respondida. Assume-se que o doutorado-sanduíche contribui para a formação do doutorando e para sua inserção no mainstream científico tanto quanto o doutorado pleno, mas não há estudo comparativo que tenha produzido evidências disso. Parece pouco razoável esse aumento acentuado do primeiro em detrimento do último quando não se tem disponíveis dados sobre a formação e o impacto de um e de outro. Aliás, relatos de casos e de experiências pessoais, assim como a observação de vários pesquisadores que, no exterior, conviveram com bolsistas dos dois tipos de doutorado, levam a pensar que são duas experiências totalmente diferentes e que formação, de fato, se dá apenas com o doutorado pleno. E por quê?

O primeiro ponto que se deve considerar é o "grau de compromisso" que se estabelece entre o estudante brasileiro e a universidade ou grupo de pesquisa ou orientador no exterior. O estudante de doutorado pleno tem sua aprovação e seu título dependentes de seu desempenho em disciplinas e no trabalho de tese realizados no exterior. Da mesma forma, a instituição/orientador vêem esse estudante como sua responsabilidade. Para poder atender às expectativas e receber seu título, o doutorando pleno tem que desvendar o funcionamento da universidade, freqüentar e ser aprovado em disciplinas em diferentes departamentos, escrever vários relatórios e trabalhos finais de disciplinas e, ainda, a tese em idioma estrangeiro, interagir com os estudantes locais e demais estrangeiros ali estudando, conhecer e usar as bibliotecas e centros de documentação, ou seja, ser plenamente socializado no sistema de pesquisa do país receptor, adquirir conhecimento codificado e tácito.

Já o doutorando-sanduíche, por sua vez, pode ficar um ano no exterior sem ter qualquer das experiências acima. Ele não depende de aprovação da universidade, o orientador não tem muito interesse na sua 
formação e muitos regressam do exterior sem terem jamais escrito um relatório ou trabalho em idioma estrangeiro. Isso não é um problema menor - saber escrever em língua estrangeira, particularmente em inglês, é uma necessidade do pesquisador hoje ${ }^{39}$. Assim, parece razoável supor, com os dados disponíveis até o momento, que o ganho em termos de formação entre um doutorado pleno e um doutorado-sanduíche no exterior é francamente favorável ao primeiro.

A defesa das partes envolvidas é, de certa maneira, esperada. A comunidade científica local (ou seja, os orientadores), freqüentemente, reclama da falta de estudantes de alto nível para a pós-graduação brasileira. São comuns os argumentos do tipo "os melhores estudantes acabam indo para o doutorado no exterior e isso prejudica a pósgraduação local", em épocas em que as agências reforçam esse programa. Os estudantes de pós-graduação, por sua vez, podem ter a experiência de viver no exterior sem boa parte das pressões colocadas por um doutorado pleno. As agências, para completar, fazem grande economia, ao mesmo tempo que podem exibir estatísticas de que o número de bolsistas no exterior não diminuiu. Ainda que se reconheça a legitimidade desses interesses, e a possibilidade de que os que os defendem estejam corretos, eles não podem ser a base da política nacional de formação de recursos humanos no exterior.

Exatamente porque a formação de recursos humanos no exterior no caso brasileiro se dá quase que exclusivamente com recursos públicos, e por ser cara, mas, acima de tudo, como se tentou argumentar exaustivamente neste artigo, por ser essa experiência essencial para a inserção do nosso sistema de pesquisa nas redes internacionais, as agências precisam ter uma política clara, amplamente discutida e aceita pelas partes interessadas. Para tanto, as agências têm que passar a ver a "formação de recursos humanos" para pesquisa como um instrumento para se atingir determinados objetivos. Ou seja, é necessário definir para que o país quer formar pesquisadores: para que sejam capazes de gerar novas tecnologias, apenas escolher tecnologias importadas, ensinar novos pesquisadores? Para trabalhar em empresas, no governo, na academia? A exemplo do que fizeram o Japão e a Coréia do Sul quando resolveram investir na formação de doutores, construindo parcerias entre governo e empresas e decidindo ter um programa com três faces (montar um sistema interno forte de pósgraduação, motivar estrangeiros para estudar em tais programas, mandar nacionais para serem treinados no exterior), a formação de 
recursos humanos deve ser parte de um projeto mais amplo. E é à luz desse projeto que se pode decidir que proporção de pesquisadores vamos formar in house ou no exterior, em que áreas, em que países e instituições, monitorando e avaliando os resultados.

Na ausência desse projeto, o acompanhamento e a avaliação do programa de formação de recursos humanos no exterior ficam totalmente descontextualizados e acabam se reduzindo a análises internas, tais como: quanto custa, quanto tempo os bolsistas levam para concluir, que proporção obtém o título, "esta tese poderia ter sido feita aqui". Evidentemente estes aspectos são importantes, mas não são objetivos em si mesmos. E até mesmo para fazer esse acompanhamento mais gerencial e interno as agências têm que se organizar; precisam manter registros sistemáticos dos quadros de pesquisadores do país (idade, local de formação, áreas do conhecimento, consangüinidade etc.); fazer uma identificação de áreas fracas no país e fortes no exterior (diagnósticos que extrapolem a consulta a alguns membros da comunidade de determinada subárea do conhecimento); ter, enfim, uma função mais ativa do ponto de vista da política e não apenas aplicar regras de procedimentos administrativos.

(Recebido para publicação em julho de 2001)

\section{NOTAS}

1. National Science Foundation - NSF, Science and Engineering Indicators 98, pp. 2-21. Versão eletrônica: http://www.nsf.gov/sbe/srs/seind98.pdf (daqui para frente farei referência a esta publicação através de seu nome reduzido: SEE Indicators 98).

2. O ano de 1995 é o mais recente para o qual se conta com estatísticas confiáveis compiladas pela NSF e publicadas no SEE Indicators 98.

3. Ver SEE Indicators 98, Table 2-25. Os estudantes estrangeiros tendem a ter uma taxa de sucesso - medida em termos da proporção de estudantes que realmente defende a tese e obtém o título dentro do tempo médio de titulação da área - maior do que a de seus colegas americanos. Assim, enquanto correspondem a $24 \%$ do alunado de doutorado, os estrangeiros recebem $33 \%$ dos títulos. Isso se dá por uma série de razões: os estrangeiros passam por um processo de seleção mais rigoroso (tanto para serem aceitos quanto para receberem financiamento) e tendem a ser a elite estudantil de seus países, são mais motivados (até porque uma fração deles pensa em 
Formação de Doutores no País e no Exterior...

ficar nos EUA e então precisa se destacar academicamente) e têm mais pressa para terminar, dado que pagam muito mais que os americanos por ano de matrícula.

4. O sistema de classificação adotado pela NSF considera como Science and Engineering as seguintes áreas do conhecimento: ciências naturais (ciências físicas, da terra, atmosférica, oceanográfica e biológicas); ciências sociais (psicologia, sociologia, ciência política, história e geografia) e as engenharias. Portanto, ficam fora das estatísticas áreas como: medicina e outras profissões médicas, educação, direito, artes, letras e lingüística etc.

5. Ver NSF, Division of Science Resources Studies, National Patterns of RED Resources: 1997.

6. Ver SEE Indicators 98, Table 2-37.

7. SEE Indicators 98 , cap. 2, p. 21.

8. SEE Indicators 98, p. XX.

9. Em 1993, as universidades nos EUA contavam com $37 \%$ de estrangeiros entre seus professores de engenharia e $27 \%$ daqueles de matemática e ciência da computação. Esses professores eram principalmente da Ásia e da Europa, sendo os maiores contingentes originários da Índia, China, Reino Unido, Taiwan, Canadá e Coréia do Sul (SEE Indicators 98, cap. 2, p. 3).

10. Para os japoneses estava bem clara a importância do conhecimento tácito. O conhecimento tácito é aquele heurístico, subjetivo e internalizado e pode ser de dois tipos: o primeiro, incorporado nas habilidades e que pode ser copiado, é passível de codificação, podendo ser articulado e escrito. O segundo é aquele que não pode ser codificado ou escrito, sendo de difícil transferência por não poder ser demonstrado; é adquirido pela experiência, tendo a interação pessoal um papel fundamental. Por isso a transferência dessa forma de conhecimento se dá principalmente através das redes pessoais (ver Nonaka e Takeuchi, 1995).

11. Informações obtidas em entrevistas com A. Arimoto, diretor do Research Institute for Higher Education, Hiroshima University, em 7/5/1996, e com K. Kitazawa, pesquisador do Department of Applied Chemistry, Faculty of Engineering, University of Tokyo, em 9/5/1996 e citadas em NSF, Division of Science Resources Studies, The Science and Technology Resources of Japan: A Comparison with the United States, Special Report, Arlington, VA (NSF 97-324).

12. NSF 97-324.

13. A grande maioria dos estudantes japoneses nos Estados Unidos está cursando a graduação (cerca de $80 \%$ do total), sendo economia e administração as áreas preferidas de estudo. A atração pela educação de terceiro grau nos EUA reside, parcialmente, na competição acirrada para entrada nas prestigiosas universidades nacionais japonesas. Muitos jovens que não conseguem passar nos exames de qualificação para essas universidades preferem estudar nos EUA porque as universidades japonesas privadas de menor prestígio, sua outra opção, são caras, exageradamente populosas e não oferecem educação de boa qualidade (NSF 97-324).

14. O número de titulados em 1995 é trinta vezes menor do que o de estudantes de doutorado naquele mesmo ano, por duas razões principais: os que se titularam em 1995 fazem parte de um contingente que iniciou o programa em torno dos anos 90, quando um número muito menor de japoneses buscava o título de doutor, dado que a ti- 


\section{Léa Velho}

tulação até essa época não era fator de diferenciação salarial no Japão (ver Yano, 1990). Além disso, as empresas que tradicionalmente financiam os estudos avançados dos japoneses nos EUA, até recentemente não deixavam seus pesquisadores permanecerem mais de dois anos na pós-graduação, período julgado suficiente para que cursassem disciplinas, complementando sua formação.

15. SEE Indicators 98 , Table 2-32.

16. SEE Indicators 98, Table 2-34.

17. SEE Indicators 98, Table 2-26.

18. Os empréstimos do Banco Mundial para o setor de C\&T da China entre 1981 e 1991 totalizaram US\$ 1,2 bilhão (SEE Indicators 98, cap. 2, p. 7).

19. S\&E Indicators 98 , cap.2, p. 29.

20. SEE Indicators 98, Table 2-32.

21. SEE Indicators 98 , Table 2-34, Table 2-9.

22. Ibidem.

23. Para dados internacionais sobre patentes, ver SEE Indicators 98 , cap. 8.

24. Vários estudos têm mostrado a importância de nacionais de um país trabalharem em outro país para aproximar os dois países em questão. Até mesmo estudantes chineses que pediram asilo político aos EUA por ocasião do massacre da Praça da Paz Celestial, e que hoje seguem trabalhando nos EUA, têm tido um papel importantíssimo na aproximação de universidades americanas com as chinesas.

25. Ver "This Year's Freshmen: A Statistical Profile", The Chronicle of Higher Education, 29/1/1999, p. A49.

26. Evidências dessa tendência para diferentes países europeus podem ser encontradas em Trow e Nybom (1991).

27. Uma excelente revisão dos estudos quantitativos sobre o papel da pesquisa básica na inovação tecnológica pode ser encontrada em Martin et alii (1996) (http://www.hm-treasury.gov.uk/pub/html/docs/spru/main.html).

28. É importante mencionar que Keith Pavitt não é um cientista que defenda a idéia da relação linear entre ciência e tecnologia à Vannevar Bush. Muito pelo contrário, Pavitt é um dos mais conhecidos pesquisadores da área de economia da inovação, o inquestionável líder hoje da prestigiosa Science and Technology Policy Research Unit (SPRU), da Universidade de Sussex, na Inglaterra, onde a grande maioria dos atuais pesquisadores em política de C\&T no Brasil se formou, com financiamento das agências nacionais.

29. Em estudo conduzido por Irvine e Martin (1980) constata-se a importância desse mecanismo através do questionamento a pós-graduados em radioastronomia sobre a relevância da qualificação alcançada na educação avançada para suas atividades profissionais na Inglaterra. Em lugar de aplicações diretas em setores específicos, o conhecimento adquirido em termos de modus operandi, tais como o desenvolvimento de sistemas operacionais ou matemáticos, revelou-se mais efetivo.

30. Diferente do que convencionalmente se pensa, recursos para a pesquisa universitária têm crescido na década de 90: até 1994, recursos para a pesquisa nas universidades americanas aumentaram cerca de US $\$ 1$ bilhão por ano em valores constantes, a partir de uma base de US\$ 15 bilhões (SEE Indicators 98 , cap. 2, p. 29). Este aumento

\section{6}


é conseqüência do crescente investimento privado em P\&D nas universidades e centros de pesquisa. O mais interessante é que tal investimento é, em boa parte, feito por empresas estrangeiras: estudo publicado no ano passado pelo Departamento do Comércio mostra que os investimentos em P\&D realizados por empresas estrangeiras nos EUA triplicaram entre 1987 e 1997. Ao final de 1998, essas empresas estrangeiras eram proprietárias de 715 centros destinados à P\&D nos Estados Unidos. O Japão é o país com o maior número de centros de P\&D: 251 unidades em 1998, seguido pela Alemanha (107), Reino Unido (103) e França (44) (ver Philip Yang, http://www2.uol.com.br/observatorio). Também no Japão ouve um aumento dos gastos com P\&D na década de 90 e, neste caso, por parte do governo, a uma taxa anual de 5,7\%, chegando a US\$ 13 bilhões em 1997 (NSF 97-324, ver nota 11).

31. Ver nota 11.

32. Vejam-se então os seguintes dados: dos 55.000 nacionais de um grupo de países (China, Taiwan, Coréia, Índia, Grécia, Alemanha, Reino Unido e Canadá) que completaram seus doutorados nos EUA entre os anos de 1988 e 1996, cerca de $22 \%$ (aproximadamente 12.000) ficaram nos EUA como pós-doutores e cerca de 9.000 aceitaram emprego, principalmente em P\&D. Esses dados variam de área para área: em computação, apenas $7 \%$ permaneceram nas universidades; em biologia, $75 \%$ daqueles que ficaram fizeram-no na qualidade de pós-doutores (Johnson e Regets, 1998). Esses dados refletem o investimento diferenciado que as empresas fazem na pesquisa in house e na pesquisa básica universitária, dependendo do seu setor de atuação.

33. Esse argumento foi defendido em dois artigos sobre a área de química no Brasil que ganharam bastante destaque na época em que foram publicados (ver Meneghini, 1991; De Meis e Longo, 1990). Ambos afirmam que a permanência de brasileiros no exterior é maior entre aqueles que lá se doutoram do que entre os que vão para o exterior como pós-doutores e que somente os bolsistas de doutorado menos talentosos retornam ao país, uma vez que os melhores lá permanecem devido às melhores condições de trabalho oferecidas. Os dois artigos, assim como a posição influente dos dois pesquisadores, chegaram a disparar um movimento no Conselho Deliberativo do CNPQ em 1993 que discutiu a possibilidade de cortar drasticamente, senão sumariamente, o programa de formação de doutores no exterior. Isto a despeito de os próprios autores admitirem que não existia informações nas agências sobre a permanência de bolsistas e que o único artigo que apresentava informações dessa natureza, e especificamente para a área de química, mostrava que, no período considerado, todos os bolsistas no exterior - doutorandos e pós-doutores - retornaram ao país dentro do período previsto (Cagnin, 1993).

34. Ver http:/ / www.capes.gov.br - Programa de Bolsas no Exterior, Estatísticas.

35. Talvez seja esta uma das razões por que o programa não cresce, apesar da prioridade que lhe é concedida pela política: professores mais velhos e já formados, com famílias constituídas e filhos em idade escolar, têm menos motivação e mais dificuldades de se deslocar para o exterior pelo período de um, no máximo dois anos.

36. Nisso o programa de pós-doutorado no exterior mantido pelas agências brasileiras difere significativamente daquele implementado pelos países avançados. Lá, o pós-doutoramento se dá imediatamente após a obtenção do título de doutor e, con- 


\section{Léa Velho}

seqüentemente, numa fase bem mais precoce da vida do recém-doutor. Basta folhear as principais revistas científicas internacionais para verificar que depois de cinco anos (ou sete anos em alguns casos raros) de doutorado as pessoas se tornam inelegíveis para as posições de pós-doutoramento.

37. Este é o grande problema de estudos como os de Meneghini (1991) e De Meis e Longo (1990) que argumentam que é mais eficiente treinar doutores no país e enviá-los ao pós-doutorado no exterior do que os doutorados plenos no exterior porque os químicos e bioquímicos professores das universidades brasileiras que se enquadram no primeiro grupo são mais produtivos que os do segundo. Na verdade, estão sendo comparadas amostras de universos com características totalmente diferentes: os do primeiro grupo são, em média, cinco anos mais velhos que os do segundo, trabalham em instituições com pós-graduação consolidada, atraem os melhores alunos (com os quais publicam cerca de $80 \%$ dos seus artigos). Para um estudo com esse objetivo, só se pode comparar semelhante com semelhante - entre os fatores que afetam a produtividade científica, apenas um deles é o local de obtenção do doutorado. Outros são: idade, tempo de obtenção do título, ambiente institucional, sistema de recompensa, facilidades para pesquisa, existência e qualidade de alunos de pós-graduação, recursos para pesquisa, carga didática etc.

38. Ver nota 9.

39. Um estudo feito entre os estudantes japoneses da Universidade de Cornell em 1994 procurou identificar a razão que levava tantos deles a fazer graduação nos EUA. Entre vários fatores, um que apareceu com bastante freqüência foi "a necessidade de aprender a escrever em inglês para poder competir em ciência, e nos negócios" (http://www.cornell.edu). 


\section{REFERÊNCIAS BIBLIOGRÁFICAS}

BEN-DAVID, J. (1971), The Scientist's Role in Society: A Comparative Study. Englewood Cliffs, NJ, Prentice-Hall.

BLUME, S. (1991), Postgraduate Research Training Today: Emerging Structures for a Changing Europe. The Netherlands, Ministry of Education.

CAGNIN, M. A. (1993), Formação Pós-Graduada no Brasil. Brasília, FLACso/CNPQ. Mimeo.

CARLSON, T. e MARTIN-ROVET, D. (1995), “The Implications of Scientific Mobility between France and the United States". Minerva, vol. 33, no 3, pp. 211-250.

CHUBIN, D. E. e ROBINSON, E. (1992), “Human Resources for the Research Work Force: US Indicators and Policy Choices". Science and Public Policy, vol. 19, nº 6, pp. 334-342.

DE MEIS, L. e LONGO, P. H. (1990), “The Training of Brazilian Biochemists in Brazil and in Developed Countries: Cost and Benefits". Biochemical Education, vol. 18, no 4 , pp. 182-188.

FINN, M. G. (1997), Stay Rates of Foreign Doctorate Recipients from US Universities, 1995. Oak Ridge, TN, Oak Ridge Institute for Science and Education.

IRVINE, J. e MARTIN, B. (1980), “The Economic Effects of Big Science: The Case of Radio Astronomy", in Anais do International Colloquium on Economic Effects of Space and Other Advanced Technologies. Paris, European Space Agency.

JOHNSON, J. M. e REGETS, M. C. (1998), “National Mobility of Scientists and Engineers to the United States - Brain Drain or Brain Circulation?". Washington, D.C., National Science Foundation, NSF 98-316, 22 de junho.

LONG, J. S. e MCGINNIS, R. (1985), "The Effects of the Mentor on the Academic Career". Scientometrics, vol. 7, $\mathrm{n}^{\text {os. }} 3-6$, pp. 255-280.

MANSFIELD, E. (1998), “Academic Research and Industrial Innovation: An Update of Empirical Findings". Research Policy, vol. 26, pp. 773-776.

MARTIN, Ben et alii. (1996), The Relationship between Publicly Funded Basic Research and Economic Performance. Relatório preparado para HM Treasury (http://www.hm-treasury.gov.uk/pub/html/docs/spru/main.html).

MENEGHINI, R. (1991), “Performance of Brazilian Scientists with Previous PhD Training in Brazil and in Developed Countries. The Case of Chemists". Ciência e Cultura, vol. 43, no 5, pp. 345-346.

NONAKA, I. e TAKEUCHI, H. (1995), The Knowledge-Creating Company. How Japanese Companies Create the Dynamics of Innovation. New York/Oxford, Oxford University Press.

OECD. (1992), Technology and Economy - The Key Relationships. Paris, OECD Publications Service.

. (1998), University Research in Transition. Paris, OECD Publications Service. 


\section{Léa Velho}

ORLEANS, L. A. (1988), Chinese Students in America: Policies, Issues and Numbers. Washington, D.C., National Academy Press.

PAVITT, K. (1991), "What Makes Basic Research Economically Useful?". Research Policy, vol. 20, no 2, pp. 109-120.

ROSSITER, M. W. (1975), The Emergence of Agricultural Science. Justus Liebig and the Americans, 1840-1880. New Haven, Yale University Press.

STRICKER, L. J. (1994), "Institutional Factors in Time for the Doctorate". Research in Higher Education, vol. 35, no 5, pp. 569-587.

TROW, M. e NYBOM, T. (eds.). (1991), University and Society. Essays on the Social Role of Research and Higher Education. London, Jesica Kingsley Publishers.

YANO, M. (1990), Personal Income Distribution and its Influence on Education in Japan. Hiroshima, Research Institute for Higher Education. 


\author{
ABSTRACT \\ Training of Brazilian PhDs at Home and Abroad: Alternative or \\ Complementary Strategies?
}

This article aims to stimulate a broad debate on the underlying logic in the policy for training researchers implemented by Brazilian science and technology funding agencies. The study was designed to answer the following question: when a country achieves domestic scientific training capability in sufficient quantity and quality, can it entirely do without training researchers abroad? The argument developed here is that the response depends on the respondent's premise. The article goes on to analyzes how different countries have dealt with the issue. Based on the data, the trend is to stimulate the mobility of human resources, especially young researchers who are still at the doctoral level. The Brazilian case is presented as "running contrary" to current trends.

Key words: science and technology; researchers training; scientific capability; doctorate abroad

\title{
RÉSUMÉ \\ Formation Doctorale au Brésil ou à l'Étranger: Stratégies Alternatives ou Complémentaires?
}

Cet article a pour but de stimuler un large débat sur la logique présidant à la politique de formation de chercheurs mise en place par les agences de financements de $C \& T$ au Brésil. Il se structure pour répondre à la question suivante: dès lors qu'un pays réussit à avoir un réseau de formation scientifique interne, pourra-t-il s'en passer totalement de former des chercheurs dans d'autres pays? L'argument que nous développons, c'est que cette réponse dépendra de qui la réponds. Nous présentons la forme dont différents pays ont réagi à cette question. La tendance, telle que les donnés la rendent évidente, va dans le sens de stimuler la mobilité des ressources humaines, notamment des jeunes chercheurs, et encore au niveau du doctorat. Le cas du Brésil est présenté comme étant à contre-courant des tendances actuelles.

Mots-clés: science et technologie; formation de chercheurs; formation scientifique; doctorat à l'étranger 